\title{
Reply to Gauthier and Gibbard
}

\section{Citation}

Scanlon, Thomas M. 2003. Reply to Gauthier and Gibbard. Philosophy and Phenomenological Research 66, no. 1: 176-189.

\section{Published Version}

http://dx.doi.org/10.1111/j.1933-1592.2003.tb00252.x

\section{Permanent link}

http://nrs.harvard.edu/urn-3:HUL.InstRepos:3201600

\section{Terms of Use}

This article was downloaded from Harvard University's DASH repository, and is made available under the terms and conditions applicable to Other Posted Material, as set forth at http:// nrs.harvard.edu/urn-3:HUL.InstRepos:dash.current.terms-of-use\#LAA

\section{Share Your Story}

The Harvard community has made this article openly available.

Please share how this access benefits you. Submit a story.

Accessibility 
[To appear in Philosophy \& Phenomenological Research]

\title{
Reply to Gauthier and Gibbard
}

\author{
T. M. Scanlon
}

I am very grateful to David Gauthier and Allan Gibbard for their thoughtful responses to my book, which are challenging and extremely helpful at the same time. They raise many points that I will have to think about, and I will be able to address only some of them here. I will begin with a few points about reasons and then go on to discuss some of the questions they raise about my version of contractualism.

Reasons

Gauthier is right that my thinking about the relation between reasons and desires has undergone a change, but this change may not be as great as he suggests. I have long been, in my heart of hearts, a believer in "external reasons." But I also thought that the idea of a reason was more problematic than that of desire, and that the clearest cases in which someone can be said to have a reason for performing a certain action are ones in which this is true because so acting can be expected to satisfy some desire that that person has. In the course of working on my book, I came to the conclusion that this view of the matter is fundamentally mistaken. It now seems to me a mistake to take desires to be psychological states, independent of reasons, that have a fundamental role in the justification and explanation of action. It is rarely, if ever, the case that someone has a reason for action because so acting would satisfy a desire. What we normally call "having a desire for $\mathrm{x}$ " is best understood as taking some consideration, such as the fact that $\mathrm{x}$ would be pleasant, as a reason to bring $\mathrm{x}$ about, and in such a case it is this consideration itself, rather than the agent's "desire," that provides the agent with a reason. 
Desires are not, then, basic sources of justification. Nor are they necessary as sources of motivation: if I take the fact that doing $\mathrm{x}$ would be pleasant, or would repay a debt, to be a good reason for action, this can suffice to explain my forming the intention to do $\mathrm{x}$ and doing $\mathrm{x}$. There is no need to posit a further state of desiring $\mathrm{x}$.

I am pleased by the degree of agreement about reasons between the three of us, which is much greater than I might have guessed. I have no objection whatever to the project of giving the kind of psychological description of deliberation about reasons that Gibbard proposes. I agree that “weighing X in favor of A isn't mysterious," but I do confess to some doubt about how a psychological description of this process of weighing "explains, indirectly, X's counting in favor of A in such circumstances." If there is any disagreement between Gibbard and me on this point, I think it is over the degree to which such an explanation is to be expected.

Briefly put, my problem is this. Any explanation of how something can count in favor of something else either explains this in normative terms, in which case it may be convincing but does not explain reasons in general, or else offers a psychological explanation, in which case the normative force of reasons is not convincingly explained. Faced with this dilemma, I am inclined to think that our inability to explain how something could be a reason is not due to a weakness in our philosophical resources but rather to the fact that the relation of being a reason for is too fundamental to be helpfully explained in other terms.

I notice that Gauthier, in stating his agreement with me about reasons, concentrates mainly on the motivational part of my claim: the claim that, in his words, "an agent is normally motivated by her judgment that something is a reason for action." I 
wonder if this emphasis may be in part responsible for the possible disagreement that he goes on to note. The point at issue is what I call "the universality of reason judgments," according to which the claim that $\mathrm{X}$ is a reason for one person to do A entails the claim that it is also a reason for anyone else whose circumstances are similar in relevant respects. I believe that this thesis is a trivial one, something close to a tautology, but that it is worth noting nonetheless. It is trivial because it leaves entirely open what "respects" are "relevant" to the determination of whether some consideration provides an agent with a good reason for a given action. In particular, the thesis of universality should not be a point of disagreement between those who hold that all reasons are based on desires and those who hold a more "objective" or "external" view: they will just disagree about what factors are relevant to determining the reasons someone has, and to making it the case that different agents have different reasons. The universality of reasons judgments seems to me worth noting, despite its tautologous character, because it imposes a useful discipline on our claims about reasons. There is a tendency, I think, to grant that others may not have the reasons we take ourselves to have without considering what this implies about the nature of our own reasons. Taking account of the universality of reason judgments forces us to make these consequences explicit, and thus to clarify the claims we are making. The (apparent) disagreements between Gauthier's view and mine serve to illustrate this point.

Gauthier says that when he takes certain considerations to afford him sufficient grounds for action "I may do this because, at least in part, of how these considerations strike me, and I need not suppose that they would strike another equally rational agent in the same way." (p. 2) If the phrase "how they strike me" is understood as making a 
purely psychological claim about how he is motivated, or about his beliefs about the reasons he has, then there is no disagreement between us here. I do not think that one person's claim that certain considerations are sufficient grounds for action entails any claim about what will "strike" someone else as a reason.

Since Gauthier takes there to be a disagreement between us on this point, however, it seems likely that he has a normative, rather than a merely psychological claim in mind. Understood in this way, the claim is that the following can be the case: X strikes one person as a good reason to do A, but does not strike another person as a good reason for this, and, because of this, $\mathrm{X}$ is a good reason for the first person to do A but not for the second. This may appear to be in conflict with the universality of reason judgments, but this disagreement is, as far as I can see, merely apparent. All that that doctrine requires is that if we claim that $\mathrm{X}$ is a reason for one of these people to do $\mathrm{A}$, but not for the other, then we are committed to the claim that there is some relevant difference between their situations. Presumably, this difference lies in how these considerations "strike them." This is a substantive claim about reasons, which is likely to be more plausible for some values of ' $\mathrm{X}$ ' and ' $\mathrm{A}$ ' than for others. When one is choosing among two activities, each of which is worthwhile, the fact that one is "drawn to" one of these, but not the other, can be a good reason for pursuing it, because indicates, for example, that one will be happier, or more likely to be successful in that pursuit. ${ }^{1}$ In other cases, however, it may be much less plausible to claim that the reasons a person has depend on how these considerations strike him or her.

Gauthier is quite right that when we disagree about whether two agents whose reactions differ in the way described above do or do not have the same reason for action, 
this disagreement cannot be settled by appeal to the universality of reason judgments. What that doctrine does, however, is to force us to identify our disagreement as a substantive disagreement about which considerations are relevant to the reasons a person has - in particular, about whether the way a considerations "strikes" an agent is or is not a relevant consideration in a situation of the kind in question. This seems to me a good example of what I called above the useful discipline that that doctrine imposes. I think it helps to clarify our understanding of such cases in a way that appeal to "the first-person focus of deliberation" does not.

\section{The Normative Basis of Right and Wrong}

Let me turn now from the question of reasons in general to that of morality. Moral requirements claim to be ones that agents have good reason to regard as authoritative and, at least normally, as overriding other considerations. The question is what reasons one has to regard them in this way. My version of contractualism answers that actions that violate moral requirements are ones that could not be justified to others on grounds that they could not reasonable reject, and that the justifiability of our actions to others is something worth caring about. Whether this answer is correct or not, I do not see how, as Gauthier suggests, it construes morality as a form of regulation that violates our selfgovernance as rational agents. Since the claim that is being made is simply that we have a certain reason to regard standards as authoritative, the only form of "regulation" involved is an appeal to our capacity for rational self-governance, so it is hard to see how that capacity is being violated, whether the claim is correct or not. ${ }^{2}$

\footnotetext{
${ }^{1}$ As I argue in What We Owe to Each Other, pp. 48-49.

${ }^{2}$ I am not proposing "the imposition of such a system [of co-deliberation] in the absence of some substantive supporting rationale" (Gauthier, p. 4) Rather, I am offering a rationale for accepting such a system.
} 
Gauthier thinks that it is not correct — that justifiability to others does not provide an adequate or convincing account of the basic reasons behind moral requirements-and he naturally prefers his own account. ${ }^{3}$ But he says in his comments that even if we were to accept the idea that we have reason to be concerned with the justifiability of our actions to others this would not provide an adequate account of the content of morality. Gibbard also expresses doubts as to whether the ideas of reasonableness and reasonable rejection can provide sufficient answers to this question. So let me turn to say something about these crucial notions.

\section{Reasonableness and Reasonable Rejection}

As Gibbard says, the idea of reasonableness I am employing is the idea of "what is supported by reasons within a contextually defined range." This is the sense in which we say, for example, that it was reasonable for someone to believe that his friend was still at work, given that he saw her car in the parking lot. In order to decide what is reasonable in this sense in a given context, we need to know what the relevant range of considerations is and make a judgment about what these considerations, taken together, support. The idea of reasonableness itself does not answer either of these questions. The context answers the first, and we draw upon our understanding of the normative significance of these considerations in order to answer the second. So, for example, a person might

\footnotetext{
${ }^{3}$ In characterizing what he sees as the difference between our two views at the beginning of his article, Gauthier interprets the title of my book more narrowly than I intended. As I understand it, he is making a particular claim about what we owe to each other. Sometimes it sounds as if his claim were that all we owe to each other is to avoid taking advantage of them- - "not bettering ourselves by worsening others without their consent." (Gauthier, p. 1) He later agrees (p. 5) that "the conventional morality of right and wrong" requires more than this. It is not clear whether he wants his view to capture some of this additional content. I assume that he does. Either way, however, I think that our
} 
understand perfectly well what reasonableness is, but be entirely in the dark, or quite mistaken, about whether a certain chess move was reasonable, because he did not understand chess well enough to see either what the relevant considerations were or what degrees of significance they had at this particular point in the game. So, although understanding the idea of reasonableness requires no understanding of chess, to claim that a certain chess move is reasonable is to make a substantive claim about that game. Similarly, although reasonableness is not itself a moral notion, certain judgments about what is reasonable have moral content.

This is so because the idea of reasonable rejection is determinate only to the degree that the relevant range of reasons and their relative weights have been somehow specified. Different ways of specifying these parameters yield different moral views, each of which could be called contractualist in a broad sense. (I will say more in a moment about my own way of doing this.) The claim that any one of these views is the correct characterization of moral right and wrong is a claim with moral content. The same is true of any claim that a certain principle is reasonably rejectable in the sense that is relevant to moral right and wrong, since any such claim presupposes that a certain specification of a range of reasons and their relative weights is morally relevant.

This might seem to leave a contractualist view open to the charge of vicious circularity, since it must begin with substantive claims about moral relevance. But this is not a serious objection. No theory, whether contractualist or not, can avoid beginning with some claim of this kind. You can't get something for nothing. What may be hoped, however, is that a theory's claims about moral relevance will be wholesale claims. That

disagreement is most clearly described as being about what we owe to each other, not about whether we owe each other anything at all. 
is, that it will identify a class of morally relevant considerations in such a way that deciding whether a given consideration does or does not fall into this class will not require a further moral judgment. So, for example, the claim that the satisfaction of any preference is morally significant would be a wholesale claim of the kind I have in mind. But the claim that the satisfaction of a preference is morally significant only if that preference is not an "anti-social" or "immoral" one would fall short, since moral judgment would be required in each case, in order to decide whether a preference was of the proper kind.

\section{The Content of Contractualism}

Two things that trouble Gauthier and Gibbard about my book have troubled many others as well. The first is that I do not specify, as clearly as they think I should, what I take to be the class of relevant reasons and their relative weights. The second is that insofar as I do specify this I do so in what seems to them an insufficiently wholesale manner, that is to say, in a way that leaves too much need for further appeal to moral judgment in working out the consequences of the contractualist formula. ${ }^{4}$ In reply let me say, first, that I doubt it is possible to specify the class of considerations that are relevant to judgments of right and wrong in a thoroughly wholesale manner. They are too diverse,

\footnotetext{
${ }^{4}$ Gibbard illustrates this worry with his scenario about the rights to oil reserves. This example is apposite insofar as it illustrates the general point, which I have acknowledged, that contractualism, like any other theory, cannot get started without some assumptions about the range of morally relevant considerations (in this case, assumptions about which reasons for objecting to an assignment of oil rights count as reasonable grounds for rejecting it.) But the example is in another respect quite atypical, since the relevance of possible objections to a division of the oil rights depends mainly on the nature of the parties' the original claims to the land (did they own it in common?) and on the nature of the "division" (were they each given just the right to use the land, or also, e.g., the right to sell it?) and on the way it was arrived at (Did they draw lots? Or bargain for parcels they thought particularly desirable?) The indeterminacy of the case seems to derive
} 
and the relations between them too complex to admit of an analysis that would draw the boundary around them once and for all.

Of course, even if there can be no wholesale account of morally relevant considerations there remains a question of degree - of how close one can get to this goal - and it may be thought that the account I have offered does not go as far as it should be possible to go. Perhaps what I have said I my book can be improved on in this respect. I would be pleased if this turns out to be so. But I believe that the goal of finding "wholesale" principles is itself commonly overrated. I think that we should look to moral philosophy primarily for advances in understanding the differences between various forms of moral evaluation and our reasons for caring about them, and in understanding moral ideas such as well-being, responsibility, and various forms of duty and obligation. These theoretical advances in our understanding will often have substantive implications, but we should not expect them generally to do this by providing general principles that will enable us to decide moral questions without appeal to judgment. Very few moral theories provide such principles, and when they do the results are not in general very convincing.

This view of the prospects for moral theory is no doubt controversial. Even if this view is accepted, however, it remains true that in order for the contractualist theory I am offering to have any determinate content it needs to include some characterization - if only a partial one — of the range of considerations that can be grounds for reasonably rejecting a principle. So I will outline briefly the characterization offered in my book,

largely from indeterminacy with regard to these antecedent facts, which do not figure in every moral question. 
responding along the way to some of the questions that Gauthier and, especially, Gibbard have raised.

Whether a principle could reasonably be rejected, depends, in my view, on a comparison of the reasons that can be offered against it with those that can be offered in its favor against alternative principles from the point of view of people who occupy various positions in a situation of the kind to which the principle applies. We never know exactly which individuals will occupy these positions in all the various situations of this kind, so questions of right and wrong must be ones we can answer in the abstract, without such knowledge. The reasons we consider in assessing a principle are therefore are not precisely the reasons that particular actual individuals have, but what I call generic reasons - reasons that people in general would have in virtue of being in the positions in question.

These include not only reasons to want to act a certain way on a given occasion but also reasons to want to be free in general to so act, and not only reasons to want others not to act, on particular occasions, in ways that would harm one but also reasons to want to be able to rely on others not acting in these ways. ${ }^{5}$ In this respect, what is under consideration in the kind of decision I imagine is the ex ante desirability, judged from various points of view, of certain principles being generally accepted and adhered to. But the points of view I take to be relevant are those of people who occupy various positions in a situation of the kind in question (that of would-be agent, possible victim, and so on), and what my view calls for is a comparison of the reasons associated with these positions. This is not to be done by taking the point of view of a person who, viewing the matter ex ante, assigns certain probabilities to his occupying one or another of these positions, and 
tries to maximize his expected utility on this basis. So if this is what is meant by ex ante desirability, then it differs from what I have in mind. (This difference is one of the reasons why contractualism as I understand it does not lead to utilitarianism.)

The need to compare the relative strength of the generic reasons associated with different positions in a situation arises because these reasons support conflicting claims. As Gauthier says, "In a particular deliberative context involving at least two persons, the possible outcome or state of affairs that one of the persons would reasonably value most highly need not be, or be compatible with, the outcome or state of affairs that the other would reasonably value most highly." What we need to compare in such a situation of conflict is the importance for a person in one of these positions of getting the outcome she prefers and the importance for the other of getting the outcome that he prefers. Comparative judgments of this kind do require a common standard for assessing what it is important for a person to have. But it does not require that there be "a universal good which all seek to realize or sustain." (Gauthier, p. 5)

The burdens that can be the basis for objecting to a principle that would disallow a certain action include the cost of not having that action available as an option, but they do not include the burden of feeling guilty, or being the object of others' resentment if one acts in that way, in violation of the principle. ${ }^{6}$ The question that is being addressed when we ask whether a principle could reasonably rejected is what we can ask of each other. The appropriateness of guilt and resentment are inescapable consequences of falling short of what we owe to others - of failing to do what principles that no one could reasonably

\footnotetext{
${ }^{5}$ See pages 203-204.

${ }^{6}$ As I explain on page 286.
} 
reject require of us. But liability to have or be the object of these feelings is not a penalty that those principles prescribe, and which therefore has to be counted as part of their cost.

Generic reasons are reasons that people in a certain situation have for objecting to a principle "on their own behalf," as Gibbard puts it. This rules out "impersonal" reasons that a person might have for objecting to a principle simply because it would lead to something that would be bad from an impersonal point of view. The restriction to reasons that people have "on their own behalves" also rules out aggregative reasons - that is to say, reasons for rejecting a principle because of the sum of its effects on many different people.

As I make clear, reasons that a person has "on her own behalf" are not limited to considerations of well-being. ${ }^{7}$ One example I mention, and that both Gauthier and Gibbard discuss, of reasons not based in well-being is the reason a person has to object to unfair principles or procedures, by which I mean ones that make distinctions for which the point or purpose of the principle or procedure provides no justification. So, for example, favoring one person simply because of his or her identity is, unless more can be said about it, arbitrary. Giving medicine to one person because he needs it more, or assigning a person to a dangerous mission because he is the one most likely to be able to carry it out, is not arbitrary. Favoring one person because he or she won the flip of a coin may or may not be arbitrary. Whether it is will depend on whether there is some reason to incorporate coin flipping into a procedure for distributing benefits or burdens of the kind in question, and on whether the coin flipping in question was part of such a procedure. Fairness may sound like a question-beggingly moral basis for objecting to a principle, as Gauthier suggests, but I do not see it as such. People have reason to object to principles 
that are unfair not because unfairness is wrong, but because they have reason not to want to be subject to arbitrary treatment.

Gibbard asks, reasonably enough, whether the exclusion of impersonal reasons is something that "falls out of my contractualist system." If my "contractualist system" is simply identified with the idea of reasonable rejection together with some specification of the relevant class of reasons, then the exclusion of impersonal reasons would simply be a part of that system, and hence "fall out of it" trivially. But the question, I take it, is whether there is some deeper characterization of my version of the contractualist idea that provides a reason for understanding reasonable rejection in a way that excludes these reasons. Briefly put, the answer is that this deeper characterization lies in the account I offer of our special reason for being concerned with that part of morality that I call what we owe to each other. This account — the idea of justifiability to others—-has implications for the content of the relevant kind of justification. But two questions arise here. The first is how fully this characterization of the normative basis of this part of morality determines its content. The second concerns the possibility of alternative characterizations of this normative basis. Examining these issues more fully will also provide an opportunity to clarify some important aspects of my view.

The reasons why it is wrong to bring about impersonally bad results, such as the destruction of the Grand Canyon, lie simply in the features that make them bad, such things as the fact that grandeur and beauty of the canyon will be lost if it is destroyed. Reasons of this kind may provide a conclusive objection to acting in a certain way, in which case it might follow that, in a perfectly general sense of "justify", we could not

\footnotetext{
${ }^{7}$ See pages $213-218$.
} 
justify such actions to others. But this lack of justifiability does not provide an additional reason for refraining from such actions.

Some people would say that the same is true of the reasons we have to help fellow humans, or not to act in ways that will injure them. What counts against such actions, in their view, is just the fact that they lead to people being killed or injured. Adding that these actions could not be justified to their victims, they would say, adds nothing. Here I disagree. Of course our thinking about such cases must begin with the fact death and injury are things that people have good reason to want to avoid. But not every way of acting that leads to someone's being killed or injured is wrong. What is at issue in the cases in question is not just the badness of these outcomes for those to whom they occur, but the wrongness of certain ways of acting - for example, ways of acting that involve taking insufficient care that others not be harmed. The question, "How much care is sufficient?" is answered not simply by considering why the outcomes in question are bad but by deciding what level of care is required by principles that we could justify to each other, principles that no one could reasonably reject. So the contractualist test of justifiability does have a role to play in these cases, not in explaining why harm is bad, but in explaining why failure to guard against harm in certain ways (but not others) is wrong.

There is, however, an obvious objection to this explanation. The question of the degree of care that we are required to exercise in order to avoid harm also arises when impersonal values are at stake- for example, when the harm in question is to natural objects or works of art, considered as valuable in themselves. In those cases, it may be said, this question is answered simply by balancing the values in question—balancing the 
disvalue of harm to these objects against the values of convenience and other competing goods. Appealing to a notion of justifiability would, again, be an unnecessary extra step. So why isn't the same true when the harm is to human beings?

The answer lies in the nature of the values in question. As I have said, in my view, to claim that something is bad, or bad for someone, is just to claim that there are reasons to respond to it in certain ways, such as reasons to want it not to occur, to regret its happening, and to try to prevent it if one can. When the occurrence in question is harm to a person, these include reasons for that person him or herself not to want it to occur. This person's reasons are not simply on a par with the reasons others also have to prevent harm to him or her: rather, they have a particularly central role as the basis for reasons that others have. If acting in a certain way would harm you, then the rest of us have prima facie reason not to act in this way because you have reason to want not to be harmed. Of course we may have other reasons to want you not to be harmed-because you have useful skills, or are a thing of beauty, or are in some other way important to the world or worthy of admiration. But recognizing your value as a rational being is a matter of responding properly to the reasons we have that flow from your reasons, that is to say, from the reasons you have "on your own behalf." (Nothing similar can be said about the Grand Canyon, which does not have any reasons.)

In my view, the requirements of that part of morality that concerns what we owe to each other are just the requirements of recognizing the value of others in this sense. But it might seem that we could do justice to this view without bringing in the idea of justifiability to a person. We might do this by saying that an action is wrong if there are reasons someone has "on his or her own behalf" that would provide good grounds for 
rejecting any principle that permitted it, even taking into account the similar reasons of others.

An account formulated in this way might lead to the same conclusions as my contractualist view about which acts are right and which wrong. What this formulation would leave out is the fact that because rational beings have reasons "on their own behalf," are able to weigh these reasons, and can have further attitudes based on them, our relations with them have a further dimension that is missing from our relations with, say, the Grand Canyon. If we govern ourselves in a way that denies the value of others by giving insufficient weight to reasons they have "on their own behalves," this gives them grounds for resentment. Moreover, we have reason to care about whether they have such grounds and, more generally, about our relations with them, by which I mean not only which attitudes they have toward us but also, and more fundamentally, which attitudes they have reason to have. This concern with our relations with others is a central component of our concern with the morality of right and wrong, and that is why it is appropriate to formulate the requirements of that part of morality in terms of what is justifiable to others rather than merely in terms of what is supported by certain reasons.

What follows from this about the grounds on which a principle could reasonably be rejected? First, that these at least include the reasons that a person has "on his or her own behalf." Second, since we are interested in the justifiability of actions to everyone, these reasons for rejecting a principle must be balanced against the conflicting reasons that others may have "on their own behalves" for insisting on it, and objecting to alternatives. (This is made explicit by the proviso, "Given the aim of finding principles that others also could not reasonably reject.") 
This much follows from the contractualist account of the normative basis of right and wrong. But does it also follow from this account that the reasons that people in various positions have "on their own behalves" are the only reasons for rejecting principles and the only reasons that must be taken into account in deciding whether such rejection would be reasonable? Taking them to be the only reasons may constitute the narrowest, and hence perhaps the purest, form of contractualism. This is the version that I expound and defend in my book. But what objection does the core idea of contractualism provide to enlarging the range of reasons that can be considered, say by including impersonal reasons? Doing so might yield what some would see as a more plausible doctrine. They may think that impersonal values are directly relevant to our duties to one another.

As I have already mentioned, however, taking impersonal reasons as grounds for rejecting a principle, and thus for counting an action as a violation of what we owe to each other, seems to me to be incompatible with a proper understanding of those reasons themselves. If impersonal reasons count decisively against an action, then this leads directly to the conclusion that that action is wrong - that is to say, that there is a decisive moral objection to it. In order to reach this conclusion it is unnecessary to bring in the idea of justifiability to others, and doing so even seems to misrepresent the reasons in question, which have nothing to do with what we owe to each other. (This is not to say that there may not be reasons of this latter kind against the action as well.)

This is what led me to exclude impersonal reasons as grounds for rejecting a principle. ${ }^{8}$ But I also allowed that impersonal values can be relevant to the reasons a person has for rejecting a principle "on his own behalf." As I have said for something to be valuable is, in my view, just for it to have properties that provide us with reasons for 
responding to it in certain ways. These include reasons to want the thing to continue to exist and not be harmed or destroyed, by ourselves or by others, and these impersonal reasons do not count as grounds for rejecting principles that would, for example, allow others to behave in ways that would destroy valuable objects. But an object's being valuable may also involve reasons to want to experience it, and to behave toward it in certain ways, for example to protect it and preserve it, and not destroy it. Although they are aspects of the value of things outside of us, these reasons are personal because they are reasons to want our lives to go certain ways-reasons to want to have certain experiences or to act one way rather than another. These reasons are thus ones that we can offer, on our own behalf, as objections to a principle that would deprive us of the opportunity to see a valuable object (perhaps by permitting others to destroy it), or prohibit us from responding to it in the ways we have reason to do-for example, by trying to preserve it.

This does not mean, however, that these reasons are all reasons of well-being. If working to save the rain forest is worthwhile, then my life may be made better by my engagement with this project. But it does not follow that my reason for doing this work would be that it contributes to my well-being. I hope that this would not be my reason. The reason I have to reject a principle that would prevent me from engaging in this worthwhile activity is thus another example of a reason for rejecting a principle "on one's own behalf" that is not grounded in one's well-being.

\section{Self-regarding Principles}

Another question Gibbard raises concerns the status of self-regarding principles, such as a principle forbidding one to smoke, or requiring one to develop one's talents.

\footnotetext{
${ }^{8}$ In Section 7 of Chapter 5.
} 
Smoking may be wrong, in the way my book is concerned with, because of the risks to others of second-hand smoke, or because of the costs to them of the smoker's premature illness and death. Similarly, we may owe it to others not to let our valuable talents lie fallow. But Gibbard observes, correctly, that in my view the ill effects of an action on the agent him or herself do not suffice to make that action wrong in the way I am describing. Why don't they? If smoking, or failing to develop any of my talents, will have serious consequences for my future happiness, why doesn't this mean that I have at least prima facie reason, on my own behalf, for rejecting principles that allow me to engage in these actions?

Gibbard suggests that such reasons should count, but that principles ruling out smoking, or failing to develop one's talents, might still be reasonably rejected because the guilt they would induce would make them a cure "worse than the disease." I am not sure about this balancing of the considerations. Is the risk of feeling guilt for smoking really worse than the risk of early and painful death? But this way of dealing with the matter is in any event unavailable to me, since in my view, as I have already mentioned, the guilt and resentment that violation of a principle might occasion do not count as reasons for rejecting it.

My explanation is different. It is simply that the part of morality that I am describing concern only our behavior toward others and the justifiability of our actions to them. This may sound not ad hoc, but it is not. The kind of guilt and resentment that is appropriate if an action is wrong in the sense I have been describing is, as I have said above, essentially concerned with our relations with others. It is thus quite different from 
the self-reproach occasioned by actions that are open to criticism from a purely selfregarding point of view.

It is of course a further question, and an interesting one, I think, whether a different kind of justifiability — in this case, justifiability to oneself—has a role to play in understanding the force and content of criticism of the latter kind, a role that is parallel to the role that, I have argued, justifiability to others plays in determining the content of morality. It may seem that it does not, because the two cases are fundamentally different. I cannot be expected always to take into account the reasons that others have, to treat them as if they were my own reasons. This would leave no room to live a life. The idea of what is justifiable to others, and the related notion of reasonable rejection, thus have a role to play in determining how I must take into account, in deciding how to conduct myself, the reasons that others have "on their own behalves." But in the self-regarding case, the reasons in question are my own to begin with. The only question is how they are to be balanced against one another, either simply in their own terms (as in the case of impersonal reasons) or within the framework of a conception of well-being. An answer to the question of what I could justify to myself would, it may seem, have to presuppose an answer to this prior question of balancing, and could therefore contribute nothing to answering it.

This view of the matter may be correct, but it is worth considering how it could not be. An argument to this effect might begin from the fact that any person has very different aims and outlooks at different points in his or her life. This diversity is, of course, not as great as in the interpersonal case. But, even so, it might be maintained that one cannot take equally seriously, at every point in one's life, the aims and desires that 
one will have at every other point (or even those that it is rational for one to have.) To do this, it might be said, would leave insufficient "room to live our life" at each point. But the decisions that we make at earlier stages of life have obvious consequences for the options we will have later. So the question arises of "what we owe" to ourselves at other times: to what degree, for example, we are required to invest in the development of talents to enlarge our future options, and to what degree we have latitude to "consume" bodily or other resources in order to pursue our present aims.

This question cannot be answered simply by substantive balancing of the merits of our present and future concerns, because we may not know what our future aims will be, or what we will choose then to do with our resources if we have them. So we need to answer it by appeal to more "generic" reasons, such as the reason we have to want to have kept open the possibility of pursuing a given kind of activity at a certain stage of life.

I trust it is clear how this might lead to a structure quite similar to the one I have defended in the case of interpersonal morality. But it would still be a different structure, marked by the fact that what is in question is the life of a single person. This difference would be shown in at least two ways. First, it appears in the normative basis of the relevant idea of justifiability: the value of living in a way one could justify to one's future self (the value of a kind of wholeness or integrity) and the disvalue of the corresponding kind of alienation from one's self over time, are different from the corresponding value and disvalue of community with, and alienation from, other people. Second, it appears in the content of the principles it would be reasonable to reject: where a single life is concerned, different kinds of sacrifice can be reasonably demanded. 
It seems to me that a view of this kind might well be the best account of prudence. Whether it is, or whether a view of the kind I described first is, ultimately, more convincing, the two possibilities illustrate another theme of my book, which I called the fragmentation of the moral. One implication of the contractualist theory of right and wrong that I offer (an implication that could well be correct even if contractualism should be rejected) is that what is commonly called "morality" involves a number of diverse values. ${ }^{9}$ I do not believe that much is to be gained by arguing over which of these values are really "moral values" and which are not—for example, over whether "duties to oneself" are moral duties. It is more fruitful, I think, to consider-as I have just been doing for the case of prudence - in what ways these values are similar in their structures and normative bases, and in what ways they differ.

\footnotetext{
${ }^{9}$ Chapter 4, Section 7.
} 